\title{
Literature review on steel fibre, silica fume and fly ash: improving methods for recycled and multiple recycled aggregate concretes
}

\author{
M. Shmlls ${ }^{1, *}$, D. Bozsaky ${ }^{1}$ T. Horváth ${ }^{1}$ \\ ${ }^{1}$ Széchenyi István University, \\ Department of Architecture and Building Construction \\ Egyetem tér 1, 9026 Győr, Hungary \\ *E-mail: maysamshmlls@gmail.com
}

Submitted: 19/10/2020; Accepted: 03/12/2020; Available online: 14/12/2020

\begin{abstract}
If all concrete is to be recycled in a future scenario, recycled concrete will be needed. Usually concrete recycling causes loss of properties, but this does not have to be truth for all the mixtures. This paper shows a comprehensive knowledge about the improving methods used to keep the properties of the recycled aggregate concrete (RAC). In the reviewed literature several kinds of RAC were tested with various replacement ratios. The effect of adding steel fibres, silica fume or fly ash to the mixture were also examined both separately and together. Most of the experiments demonstrated excellent mechanical properties of the RAC compared with ordinary concretes. Based on these results the ideal RAC composition can be deduced and a future can be imagined when concrete can be recycled multiple times (MRAC).
\end{abstract}

Keywords: recycled coarse aggregate; steel fibre; silica fume; fly ash; multiple recycled aggregate concrete

\section{Introduction}

Concrete is a global and basic construction material primarily used at civil engineering works. Aggregate gives about $70-80 \%$ of the concrete. There is shortage of aggregate materials due to the increasing demand of this raw material in all over 
the world. Therefore, it is important and beneficial to focus on recycling this material and to solve the environmental problems by reducing the use of conventional concrete. Scarcity of natural resources and impacts of climate change have made the increasing consumption of resources an important issue, especially in the case of building materials such as cement, fine and coarse aggregate. Simultaneously, there are massive amounts of waste materials generating from demolitions of old buildings or remaining as debris after the wars all over the world.

Because of these two points, the definition of recycled coarse aggregate was created to reach sustainable construction and to decrease the cost of aggregates. Many researchers have studied recycled aggregate concrete (RAC) and the effects of recycling on the fresh and hardened properties of concrete. The results were different in the cases of different concrete types containing cement replacement materials and other additions such as superplasticizer and steel fibres. For many decades, steel fibres have been used in reinforced concrete to reduce the numbers of cracks and provide ductility inside the concrete. However, just a few studies focused on the effect of steel fibres on durability and compressive strength of RAC containing cement replacement materials such as fly ash and silica fume.

This paper reviews what scientific knowledge found about recycled aggregate concrete and what the fresh and hardened properties of different concrete admixtures are, compared with the case of the controlled concrete. In addition, it answers these questions: Do the cement replacement materials (fly ash or silica fume) (Fig. 1) play a significant role in the concrete field? What kind of materials can be used effectively? What is their effect on the properties of normal and recycled aggregate concrete? Can the RAC properties improve with the addition of steel fibres, or not?
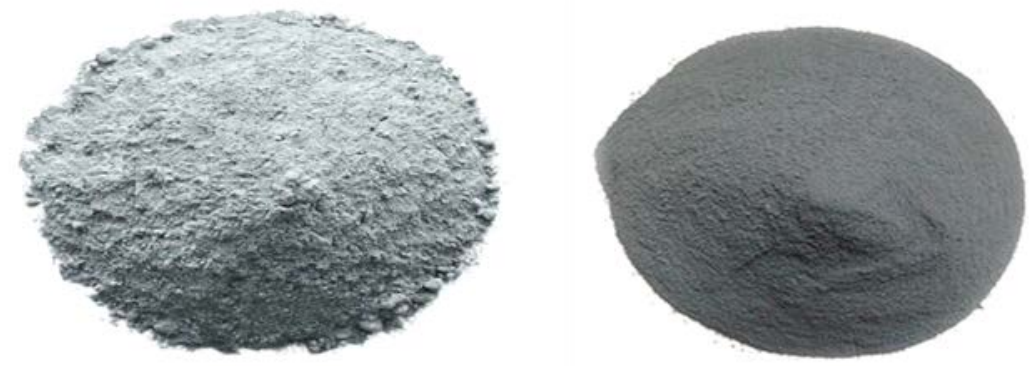

Figure 1. Fly ash (left) and silica fume (right) supplement materials [1][2]

Silica fume is a by-product in the processing of simple silicone or silicone alloys in electric arc furnaces. The reduction of high pure quartz into silicone at a temperature of about $2000^{\circ} \mathrm{C}$ creates silicone dioxide vapor that changes its physical 
state and becomes silica smoke at low temperatures. Silica fumes have a solid surface and extremely fine average size $0.1-0.3 \mu \mathrm{m}$ [1]. The early slump of fresh concrete is to be raised to improve the workability. The silica fume has been proven to lower bleeding by its impact on rheological products [3] [4]. Test results revealed that silica fumes have limited significance in the development and stabilization of the air avoidance system. Resistance experiments (ASTM C666) on silica concrete produced reasonable results like the average factor of longevity was above $99 \%$.

Waste fly ash (WFA) typically consists of small carbon-burned fragments and has many uses. Its material content thus depends on the origin and nature of the coal used. In many countries, fly ash formed by the burning of coal in power stations presents large environmental and economic problems. Snelson and Kinuthia [5] proposed the addition of WFA as a partial replacement of cement to enhance properties of concrete. In addition, they studied WFA with cement paste to confirm the ability of using WFA on physical, mechanical and activation behaviour of concrete. The typically specified rate of substitution of fly ash for Portland cement is 1 to $11 / 2$ pounds fly ash for 1-pound cement. Nevertheless, it depends on the researcher's experiments and what kind of mixtures are to be tested.

\section{Types of steel fibres and an its use in concrete}

In order to improve the properties of concrete, several types of fibres are used in the construction practice an in research. Fibres can be made of plastic, glass, carbon, or steel (Fig. 2). Steel fibre is a small piece of metal reinforcement with different aspect ratio (length, diameter) that can reach up to $100 \mathrm{~mm}$ length, having different forms and endings (straight, crimped, stranded, hooked, and twisted fibre), as it is shown in Fig. 3 [6]. 


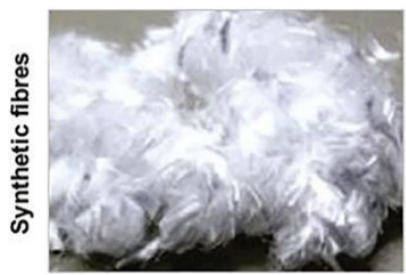

Polypropylene

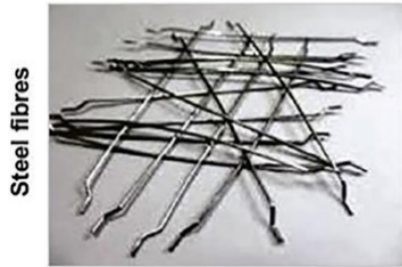

Hooked-end

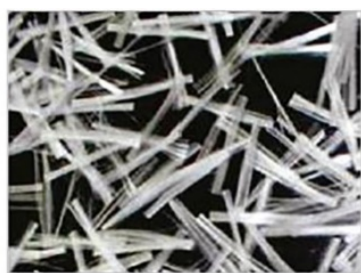

Glass

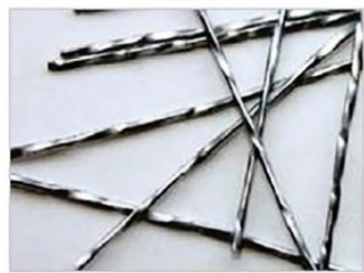

Twisted

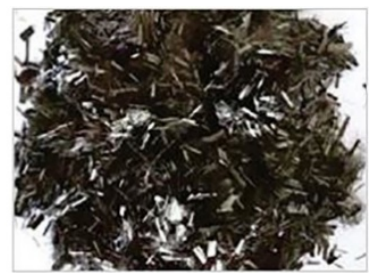

Carbon

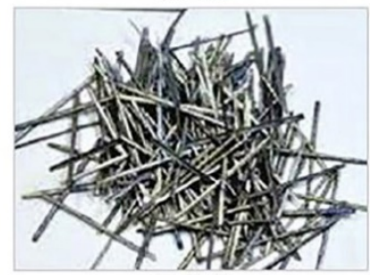

Straight

Figure 2. Fibres commonly used to reinforce concrete [6]
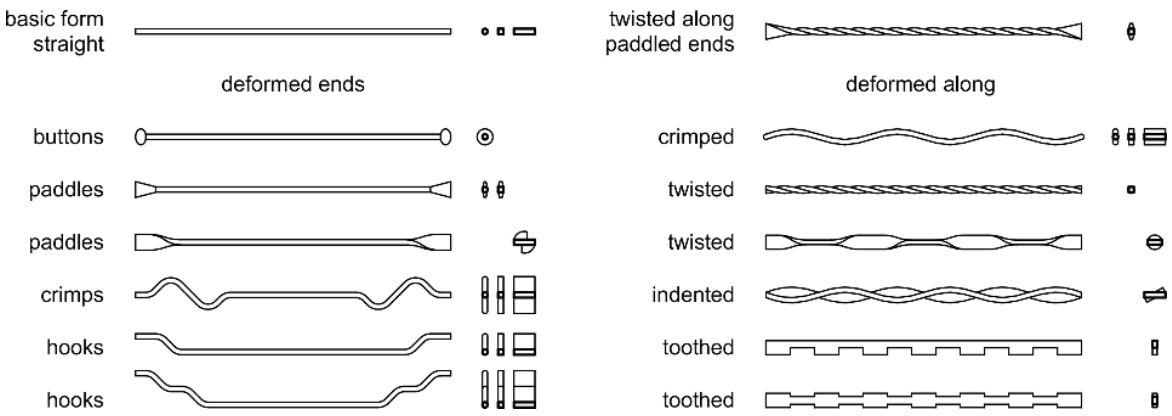

Figure 3. Types of steel fibres [original drawing]

There are five groups of steel fibres based on the shape and industrial process of production: mill cut, melt-extracted, cut sheet, cold-drawn wire, modified colddrawn wire. The greatest benefits of steel fibre utilization in concrete is to reduce the number of cracks which can happen on the surface of concrete, to increase its resistance on high temperatures and against exterior impacts, to improve other concrete properties such as banding capability, durability, weakness, and fatigue.

\subsubsection{Steel fibres in ultra-high-performance concrete (UHPC)}

In different fields of civil engineering (construction of bridges, decks, slabs, industrial pavements) steel fibres play an important role. Brandt's study [7] focuses on the production of the evolving ultra-fibre reinforced concrete and explains that 
steel fibres can reduce the amount of cement in concrete and thus its carbon footprint and environmental impact can be reduced. This experiment substituted the 50\% weight of Portland cement with fly ash and ground granulated blast-furnace slag in half proportion, and the results showed that UHPC mixtures approached 125 and $140 \mathrm{MPa}$ compression strengths at the ages 28 and 56 days. The flexural strength test results showed that UHPC with the maximal fibre fraction (i.e. $2.5 \%$ by volume, comprising $1.5 \%$ hooked fibres, and $0.5+0.5 \%$ long and short micro wire fibres) attained adequate flexural and uniaxial compressive strength for post cracking ductility and sub-peak load holding. Brandt [8] explained that steel fibre reinforced high-strength concretes can be excellent solutions in critical areas where earthquakes are frequent because of their high compressive strength, ductility, and adequate seismic structure.

\subsubsection{Steel fibres in light-weight concrete (LWC)}

Kalpana and Tayu [8] described their study about the incorporation of the waste steel fibres in lightweight concrete. Their results showed that even a small quantity of fibre is able to improve the composition of lightweight concrete and prevent it from the brittle failure, and the effect of steel fibres on the flexural strength is far greater than their direct stress or compression influence. Moreover, it was observed that the LWC strength was found to depend on the quantity of fibre content, the best fibre ingredients vary with the quality demands to achieve the greatest profit in diverse strengths. As the fibre content increases, failure mode is changed from brittle to ductile once subjected to compression and bending. The incorporation of steel fibre is an important factor in fragility reducing.

Rico et al. [9] added steel fibres into a delicate cement matrix, according to their research, in order to increase the break resistance of the LWC by the split capture process and to improve the tensile and flexural properties. The results showed that steel fibre played a connection role inside the concrete thus helping to raise the resistance of the concrete against cracks and mentioned that increased toughness is a consequence of increased fibre.

\subsubsection{Steel fibre in self-compacting concrete (SCC)}

In the study described in Ramesh et al. [10], different rates of steel fibres $(0.3,0.6$, $0.9,1.2 \%$ ) had been used in self-compacting concrete mixtures to measure the effects of the fibres for the mixtures, to study the workability and the strength properties. According to the results, the flexural and break tensile strength improved for the 7th day in case of SCC incorporation and steel fibres compared to the control concrete (with no steel fibres), but the improvement was not considerable. For the 28th day, the bending intensity and the split tensile strength improved significantly (15-21\%) when fibres were applied compared to the reference concrete. 
Dhaher [11] presented his experimental investigation on the fracture behaviour of hybrid fibre reinforced self-compacted concrete. In the experiments, two forms of fibres were used: steel and polypropylene fibres. Volumetric fibre percentages were implemented: $0.75,1.0$ and $1.15 \%$ for steel; $0.10,0.15$ and $0.25 \%$ for polypropylene. In comparison, a $0.75 \%(0,65 \%$ steel and $0,10 \%$ polypropylene fibre) combination mix of the above-listed forms have been used. This was the only formula that managed to meet the new demands of self-compacting concrete. The test results show that the fresh-state properties considerably decreased if fibres are incorporated into the SCC blends. The SCC criteria could be achieved only by the mixtures of volumetric percentages of $0.75-1.00 \%$ steel and $0.10-0.15 \%$ polypropylene fibres. The use of steel fibres also works more than the use of polypropylene fibres regarding all forms of strength. The increase in-group intensity for any measured combination was far greater than that of compressive strength. During the experiments, Dhaher [11] also observed that a link-cracking area evolved due to the incorporation of fibres regardless of the type and amount.

\section{The necessity of recycled coarse aggregate (RCA)}

Concrete is in the first place among the list of construction materials because of its massive advantages. However, concrete production also emits immense amount of $\mathrm{CO}_{2}$, which affects the environment and climate. Moreover, researchers estimate the amount of raw concrete materials, such as cement, fine and coarse aggregate, water, to be about 20 billion tons per year with increasing demand year by year [12]. Zhang et al. [13] mentioned that the global concrete production in each year is between $13-21$ billion tons, and in this amount $49 \%$ is the aggregate (gravel and fine), and $16 \%$ is water.

Concrete demolition waste to be recycled is estimated about 850 million tons/year in European countries and about 200 million in China. The challenge is the same in the Middle East countries, such as Gaza strip and Syria where a huge amount of debris resulted from the ruined buildings due to the constant wars. The estimated concrete debris amount is about 2 million tons in the Gaza strip after the war in 2014, and until now, there are no statistics on the extent of huge destruction in Syria, which can be seen in Fig. 4. 


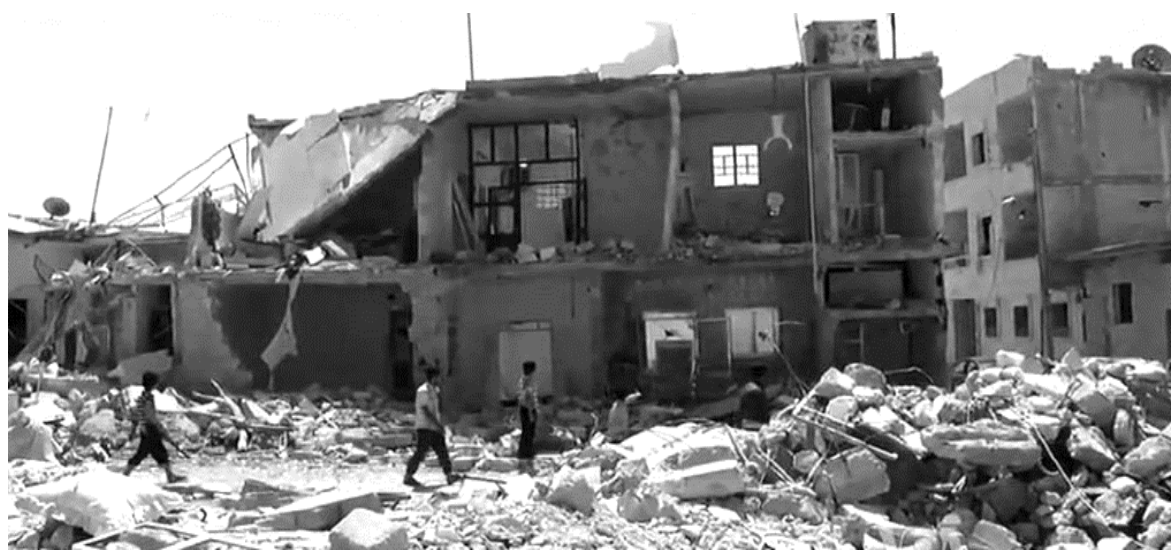

Figure 4. Destroyed place in Syria, with concrete debris [14]

Aggregate as the biggest part of the concrete (usually about two-thirds) is an essential element that needs to be highlighted by doing lots of experiments and detailed research to sustain the balance in the construction trade taking into consideration the growing demand of this material. In addition, some countries are struggling to obtain this raw material because it is not available in a sufficient quantity and quality from domestic sources for the continuous constructions (Fig. 5). Based on all these factors, the recycled coarse aggregate (RCA) is playing a significant role in the construction field, which still needs more future studies.

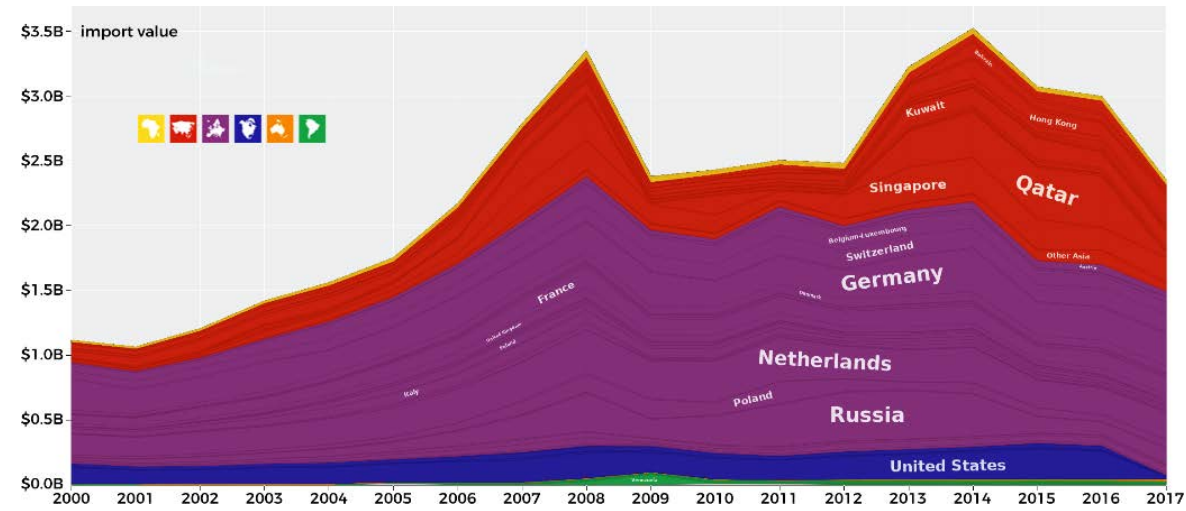

Figure 5. $\quad$ Crushed stone and gravel import between 2000-2017 [15] 


\section{The recycled aggregate concrete and its improvement}

RCA is not a brand-new concept; it was used during and after the World War II to get rid of the tremendous amount of debris generated from demolitions and construction waste. Firstly, instead of natural aggregate (NA), used recycled aggregate (RA) was applied as a bedding in the substructure of a road in England [16]. Then researchers initiated the investigations of the possibilities for the replacement of NA with RA in the building structures. Rahal [17] found, during his experiments, that the compressive strength of the recycled aggregate concrete (RAC) was reduced and the same thing happened for modulus of elasticity. However, researchers continued in this field to improve and adopt RCA by adding an unprocessed material to provide a concrete admixture, which can be similar to the control concrete with same properties.

\subsection{Using fly ash (FA) in RAC}

Recycled aggregate concrete also reduces the cost of making concrete up to $30 \%$ [18]. Many researchers studied the ability of RAC with different replacement amount of natural aggregate. These studies usually confirmed the reduction of the compressive and tensile strength [19] [20] [21]. However, some of them found the opposite results [22]. To decrease this effect on the strength of RAC, some researchers used cement replacement materials such as fly ash, waste cellular concrete or waste perlite powder to modify the strength of RAC. Snelson and Kinuthia [5] explained the positive effect of fly ash on the mechanical properties and durability when fly ash was partially replaced with cement. There are also different names for this supplementary material such as unprocessed material, rejected material, low-quality material, or raw material.

Abed and Nemes [23] added three type of supplementary materials to the cement in different admixtures with different replacement amount of recycled aggregate (RA). The most important points in their results showed: (1) There is some increase in the compressive strength at the age of 90 and 270 days, when the fly ash ratio was $15 \%$ and the RA replacement was $50 \%$ of the NA. (2) Result is almost the same by using waste perlite powder in 15\% ratio. (3) But for the splitting tensile strength, their experiments showed that $15 \%$ waste perlite powder made the RAC with $25 \%$ and $50 \%$ of NA replacement slightly stronger than adding the same dosage of fly ash or the waste cellular concrete.

Chandragiri and Cao [24], Vieira et al. [25] and Laneyrie et al. [26] found that after exposure to elevated temperature, the properties of concrete were affected and the residual mechanical properties became enhancing, and the explosive spalling of concrete decreased. The incorporation of pulverized fly ash and the slag in two separate admixtures showed an important effect to save the residual mechanical 
properties, to reduce the exterior cracks and to decrease the possibility of spalling after the concrete's exposure to high temperature [27] [28].

\subsection{Using silica fume (SF) in RAC}

In the research of Pilehvar et al. [29] demolition structure waste is used as RA in concrete mixtures, with or without SF. The mechanical properties of the concrete specimens are defined in three groups, such as compression strength, tensile strength, and physical properties of the specific concrete specimens, such as the density of the water absorption rate. The optimal ratio in concrete combinations is implemented as $30 \%$ of RA. Low RAC regression factor with SF is observed in the short term. It has been found that the 5\% SF content of the RAC improves the low features of the RAC more easily.

The effects of SF in the concrete blend are described by Cakir and Sofyanli [30], to improve the quality of recycled concrete. Portland cement has been replaced at $0 \%, 5 \%$ and $10 \%$ by SF. Specimens were produced by substituting natural aggregates for recycled aggregates. Four group of concrete mixtures and two size fractions (4/12 and 8/22 mm) were used. A consistent water / binder proportion of 0.50 has been used in all mixtures and concrete were prepared with a preliminary target slump of the class S4 $(16$ to $21 \mathrm{~cm})$. The results showed that mechanical and physical characteristics of concrete were enhanced by $10 \% \mathrm{SF}$ as cement replacement for RAC. The tensile strength increases in the NA concrete mix with and without SF was higher during all the test times than that of the RAC mixtures. The strength of the RAC incorporating SF was observed for continuous and significant improvement. Concrete with $10 \% \mathrm{SF}$ and $4 / 12 \mathrm{~mm}$ fraction RA have shown improved performance between recycled compound concretes.

Contrary to the above-mentioned studies, Adebakin and Piaye [31] noticed in their study that adding silica fume has negatively affected on the residual strength and raised the surface cracks on the concrete.

\subsection{Using steel fibre in RAC}

Gao et al. [32] investigated the durability of steel fibre reinforced recycled coarse aggregate concrete (SFRRAC) by doing carbonization, quick freeze-thaw, and chloride penetration tests. Different replacement amounts of coarse aggregate were used, which were made of waste old mixture concrete with compressive strength from 30 to $50 \mathrm{MPa}$. The replacement ratio was $0,30,50,100 \%$ of the normal coarse aggregate. Steel fibre was used as reinforcement with the ratio $0,0.5,1,1.5,2 \%$. The experimental results showed that: carbon tolerance, freeze-thaw resistance, and antichloride permeability improved with compressive strength. SFRRAC's durability indicators were more susceptible to water binding than to compression strength. A 
less water-cement ratio improved the durability. The experimental results showed the followings: (1) The recycled aggregate replacement ratio had a low effect on carbonate strength, freeze-thaw resistance and anti-chloride permeability with the same compressive strength and steel fibre volume fraction. SFRRAC's durability is like normal concrete. (2) Steel fibres also increased the durability of SFRRAC as they did for ordinary concrete. If the fraction of steel fibre was less than $1.5 \%$, SFRRAC's durability increase with the fraction of stainless fibre volume. Nevertheless, the durability became slightly lower with the rising fibre amount of steel, when the steel fibre fraction was higher than $1.5 \%$. (3) The $5 \%$ weight loss was not an adequate failure standard for the SFRRAC rapid freeze-thaw test. A further study is required to determine the suitable failure test of the SFRRAC fast freeze-thaw test. (4) Concrete compactness was the main factor that affected the SFRRAC's durability. SFRRAC is a long-lasting material and can be applied successfully as structural elements with good blending design.

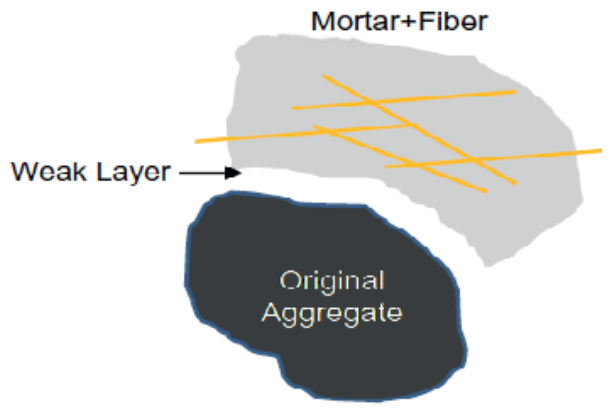

Figure 6. Composition of recycled concrete with steel fibres [33]

Kunieda et al. [33] investigated the possibilities of recycling fibre concrete, which included different types of fibres, as well as steel fibres. The content of fibres had different ratios: $0.2 \%, 0.5 \%, 1.0 \%$ polypropylene, and $1.0 \%$ steel fibre. The crushing process was made by a jaw crusher machine, which had 38 ton/h capacity. The findings of these recycling experiments were the followings: (1) With an increase in the fibre content, the size of crushed concrete in recycled fibre concrete decreased, because the fibre in the mortar reinforced the cracked parts and caused other damage. They also noticed that the distribution of particle size did not significantly differ between the normal and PP fibre concrete, only by 0.2 percent. (2) The crushing phase was performed in this experiment by using a jaw crusher, which is ordinary, used to produce recycled aggregate from concrete. The fibre content can be easily removed through the operation. Fibres are stored in the mortar and the processing of admixture is the same as that in the control concrete, as it is shown in the Fig. 6. (3) Researchers noticed that adding the steel fibres caused reduction in the compressive 
strength but slightly increased the flexural strength and toughness. (4) During the experiments, the air content increased from 3.8\% to $9.8 \%$ in the new mixture with steel fibre. The $1 \%$ fibre content could lower the water absorbance ratio by more than $1 \%$ compared to regulated concrete and thus decrease the installed mortar around the recycled coarse aggregate.

\subsection{Using couple effect of silica fume and steel fibre in RAC}

Adding steel fibre with silica fume to RAC can lead to a future structural material with less crack in the RAC, reduction in the water permeability, increasing in both compressive and flexural strength [34]. Xie et al. [35] used the pair effect of silica fume and steel fibre to experiment the compressive strength and flexural performance of RAC. Adding of silica fume had done with two ways: the equal quantity substitution was $0,5,10 \%$ (depending on normal performance and cost calculation), or the straight addition was $3 \%$. Steel fibre ratio was $1 \%$ and polypropylene ratio was $0.13 \%$ of the concrete volume. The replacement amount of recycled aggregate was $100 \%$. 39 cylinders $(150 \times 300 \mathrm{~mm})$ and 39 prisms $(100 \times 100 \times 515 \mathrm{~mm})$ have been made for testing. At the age of 90 days, the experiments were made on the samples, and these showed that: (1) The perfect percentage of silica fume is $10 \%$ to improve the compressive and flexural strength of SFRRAC. (2) The pair effect of silica fume and steel fibre is stronger than the pair effect of silica fume and polypropylene. (3) Adding the silica fume can improve the interfacial bonding between the cement paste and the thick steel fibres. (4) 1.5\% of steel fibre had improved the flexural strength. Table 1 . shows the most important results for this couple effect of silica fume and steel fibres demonstrated in this study.

Table 1. Couple effect of steel fibres and silica fume on RAC properties

\begin{tabular}{|c|c|c|}
\hline $\begin{array}{c}\text { Properties } \\
\text { of RAC }\end{array}$ & $\begin{array}{c}\text { Adding only steel } \\
\text { fibres to RAC }\end{array}$ & $\begin{array}{c}\text { Adding steel fibres and } \\
\text { silica fume to RAC }\end{array}$ \\
\hline Compressive strength & Reduced up to $10.8 \%$ & Increased up to $9.1 \%$ \\
\hline Flexural strength & Slight effect & Significant effect \\
\hline Modulus of elasticity & Reduced up to $13.9 \%$ & Increased up to $5.0 \%$ \\
\hline Toughness & Increased with $9 \%$ & Increased over $50 \%$ \\
\hline
\end{tabular}

\section{Multiple recycled concrete aggregate (MRCA)}

Recycling of concrete as aggregate should be an essential method in the building industry. In this way, the $\mathrm{CO}_{2}$ emissions of natural stone extraction can be reduced [36], as well as the cost of construction of new buildings. Especially in developing 
countries which have been facing tough circumstances over the past few years, such as Syria which suffers from an economic crisis due to the second local war since 1980. Wars have produced a lot of construction debris and wastes. The reconstruction cost is estimated at 250 billion dollars by the United Nation. The demolition and construction wastes, which need many landfills, have an increasing amount each year. 850 million tons is the yearly generation of C\&D waste in European countries, while the annual amount in China is 200 million tons [13]. These facts explain the necessity for the research of recycled coarse aggregate and even the possibility of multiple recycling.

Only a few studies investigated the mechanical and other properties of the multiple recycling coarse aggregate concrete (MRAC) with different replacement amounts. Thomas et al. [36] presented by using computerized microtomography that the adhered mortar volume of multiple recycled coarse aggregate (MRA) could be up to $80 \%$. When the mechanical and physical properties were compared between the first generation and the multiple recycled concrete in the precast industry, the findings of Salesa et al. [37] showed perfect mechanical performance of MRAC. The results showed that MRAC was superior to the control concrete of precast concrete samples and they supported the idea of adopting MRAC as a sustainable method of recycling.

Huda and Alam [38] presented different conclusion when they used replacement up to $100 \%$ in the MRAC: the compressive strength was marginally reduced. Marie and Quiasrawi [39] used only 20\% replacement of MRA to study the closed-loop conduct. Their results also showed some reduction in the tensile and compressive strengths. In general, they proved that the performance and the possibility of using MRA were still satisfactory. They used MRA's closed-loop process, because recycling was important to compensate the natural scarcity, to achieve sustainability, and to reduce climatic changes at least in the construction field as it is shown in the Fig. 7. The experimental results of Abed et al. [40] showed less porosity and the same pressure resistance for the second-generation of recycling in comparison to those shown by the normal control concrete. 


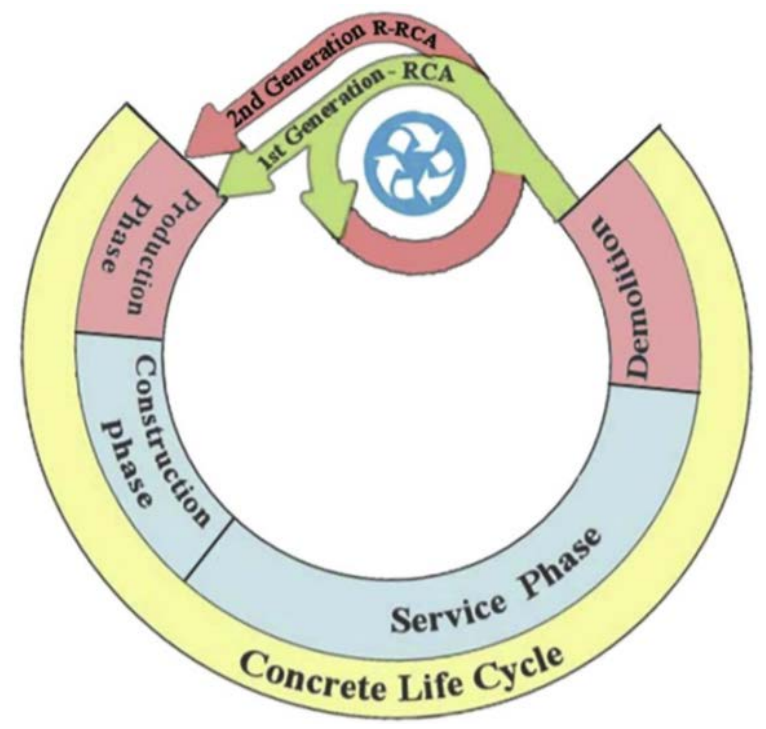

Figure 7. Closed-loop recycling of coarse aggregate [39]

\section{Discussion}

The aim of this paper was to review what the researchers have discovered so far in the concrete field about the impact of steel fibre on the concrete types, especially in the two generations of recycled concretes (RAC and MRAC). It also showed what the effect of additional materials such as (fly ash, silica fume and steel fibre) is on the recycled concrete's properties.

Using $2.5 \%$ volume of steel fibre in ultra-high-performance admixture provided a perfect concrete with high compressive and flexural strength in the regions exposed to earthquakes constantly. Lightweight concrete interacted with the steel fibre in a perfect admixture causing some increase in the crack resistance and playing a connecting role among the concrete particles. For self-compacting concrete, different rates and types of steel fibre were tested to measure the impact of these materials in this kind of concrete. Table 2. presents a summary of the effect of steel fibre on mechanical properties of each concrete category. 
Table 2. Effect of steel fibre on properties of different concretes

\begin{tabular}{|c|c|c|}
\hline \multirow{2}{*}{ Types of concrete } & \multicolumn{2}{|c|}{ The effect of steel fibre on mechanical properties } \\
\cline { 2 - 3 } & $\begin{array}{c}\text { Compressive strength } \\
\text { and crack reduction }\end{array}$ & Tensile strength \\
\hline $\begin{array}{c}\text { Ultra-high-performance } \\
\text { concrete }\end{array}$ & $\begin{array}{c}\text { High compressive } \\
\text { strength up to } 140 \mathrm{MPa}\end{array}$ & $\begin{array}{c}\text { Adequate flexure and } \\
\text { uniaxial strength }\end{array}$ \\
\hline $\begin{array}{c}\text { Light weight } \\
\text { concrete }\end{array}$ & $\begin{array}{c}\text { Prevent from brittle } \\
\text { failure and turn into } \\
\text { ductile / reduce }\end{array}$ & $\begin{array}{c}\text { Increase the break } \\
\text { resistance }\end{array}$ \\
\hline $\begin{array}{c}\text { Self-compacting } \\
\text { concrete }\end{array}$ & $\begin{array}{c}\text { Link-cracking area had } \\
\text { been improved }\end{array}$ & $\begin{array}{c}\text { Significantly } \\
\text { improvement }\end{array}$ \\
\hline
\end{tabular}

Fly ash with $15 \%$ replacement of cement was the best ratio, it had a positive effect on mechanical properties and the durability of RAC and saved the residual mechanical when RAC was exposed to high temperatures. Silica fume was observed in the short term. It has been found that the $5 \%$ silica fume content of the RAC improves the low features of the RAC more easily. Adding $5 \%$ of silica fume resulted satisfactory properties in the RAC, but another researcher tried a different ratios of silica fume $(0 \%, 5 \%, 10 \%)$ and found that $10 \%$ was a perfect ratio to improve the properties of RAC. Unlike others who noticed in their study, that adding silica fume negatively affected the residual strength and raised the surface cracks on the concrete. Main findings from the studies:

- Adding the steel fibres to RAC caused a reduction in the compressive strength and slightly increased the flexural strength and toughness. In addition, air content inside the samples increases from 3.8\% to $9.8 \%$ after the new mixture with steel fibre. Another researcher noticed that $1.5 \%$ of steel fibre improved flexural strength.

- The combined effects of steel fibres and the $10 \%$ silica fume will contribute to the potential structural material of RAC with less cracking.

- The pairing effect of silica fume and steel fibre is stronger than the pairing effect of silica fume and polypropylene.

- Adding silica fume can improve the interfacial bonding between the cement paste and the thick steel fibres.

- The compression and strength tests on the MRAC proved close results to those tests performed on the control concrete. 
As a result of reviewing the scientific literature of the recycled aggregate concrete topic, some research directions can be inferred for future researches:

- Using the triple effect of steel fibre, fly ash and silica fume can provide an optimum concrete admixture with excellent compressive and flexural strength, minimum cracks on the surface and high-temperature resistance.

- Multiple coarse aggregate concrete still needs further research and more laboratory experiments to test the fire resistance and freeze/thaw effect.

- Using supplementary materials, the properties of MRAC can be improved and the missing properties can be defined in a future research.

\section{Acknowledgement}

The author would like to acknowledge the financial support of the project EFOP3.6.1-16-2016-00017 - Internationalization, initiatives to establish a new source of researchers and graduates, and development of knowledge and technological transfer as instruments of intelligent specializations at Széchenyi István University.

\section{References}

[1] D. K. Panesar, Supplementary cementing materials, in: S. Mindess (ed.), Developments in the Formulation and Reinforcement of Concrete, Woodhead Publishing, 2019, pp. 55-85.

doi: https ://doi .org/10.1016/B978-๑-08-102616-8.00९९3-4

[2] M. Pigeon, R. Cantin, Flexural properties of steel fibre-reinforced concretes at low temperatures, Cement and Concrete Composites 20 (5) (1998) pp. 365-375.

doi: https ://doi.org/10.1016/S0958-9465(98) 00017-1

[3] R. Pérez-López, J. M. Nieto, G. R. de Almodóvar, Utilization of fly ash to improve the quality of the acid mine drainage generated by oxidation of a sulphide-rich mining waste: Column experiments, Chemosphere 67 (8) (2007) pp. 1637-1646.

doi: https://doi .org/10.1016/j . chemosphere. 2006 .10.009

[4] S. M. Levy, Calculations Relating to Concrete and Masonry, in: Construction Calculations Manual, Butterworth-Heinemann, 2012, pp. 211-264. doi: https ://doi .org/10.1016/B978-0-12-382243-7. 00९०5-X 
[5] D. G. Snelson, J. M. Kinuthia, Characterisation of an unprocessed landfill ash for application in concrete, Journal of Environmental Management 91 (11) (2010) pp. 2117-2125.

doi: https ://doi.org/10.1016/j . jenvman .2010.04.015

[6] T. E. T. Buttignol, J. L. A. O. Sousa, T. N. Bittencourt, Ultra-highperformance fibre-reinforced concrete (UHPFRC): a review of material properties and design procedures, Revista IBRACON de Estruturas e Materiais 10 (4) (2017) pp. 957-971.

doi: https ://doi.org/10.1590/s1983-41952017000400011

[7] A. M. Brandt, Fibre reinforced cement based (FRC) composites after over 40 years of development in building and civil engineering, Composite Structures 86 (1-3) (2008) pp. 3-9.

doi: https ://doi.org/10.1016/j.compstruct . 2008. 03.006

[8] M. Kalpana, A. Tayu, Experimental investigation on lightweight concrete added with industrial waste (steel waste), Materials Today: Proceedings 22 (3) (2020) pp. 887-889. doi: https ://doi.org/10.1016/j . matpr. 2019.11.096

[9] S. Rico, R. Farshidpour, F. M. Tehrani, State-of-the-art report on fiber-reinforced lightweight aggregate concrete masonry, Advances in Civil Engineering (Special Issue) (2017) p. 9. doi: https://doi.org/10.1155/2017/8078346

[10] B. Ramesh, Review on the flexural properties of fibre reinforced self-compacting concrete by the addition of M-sand. Materials Today: Proceedings 22 (3) (2020) pp. 1155-1160. doi: https ://doi .org/10.1016/j . matpr . 2019.12.041

[11] A. S. Dhaher, Fracture behaviour of reinforced self-compacting concrete with hybrid fibres, M.Sc. thesis, University of Technology, Iraq, (2016). URL https://WWW. researchgate.net/publication/292157685

[12] A. M. Wagih, H. Z. El-Karmoty, M. Ebid, S. H. Okba, Recycled construction and demolition concrete waste as aggregate for structural concrete, HBRC Journal 9 (3) (2013) pp. 193-200. doi: https://doi.org/10.1016/j.hbrcj.2013.08.007 
[13] Y. Zhang, W. Luo, J. Wang, Y. Wang, Y. Xu, J. Xiao, A review of life cycle assessment of recycled aggregate concrete, Construction and Building Materials 209 (2019) pp. 115-125. doi: https ://doi .org/10.1016/j . conbuildmat . 2019.03.078

[14] L. Vignal, Destruction-in-Progress: revolution, repression and war planning in Syria, Built Environment 40 (3) (2014) pp 326-341. doi: https ://doi .org/10.2148/benv. 40.3.326

[15] The Observatory of Economic Complexity: Which countries import Gravel and Crushed Stone? (2000-2017) [cited 2020-09-25].

URL https://oec.world/en/visualize/stacked/hs92/import/ show/all/2517/2000.2017/

[16] N. Kisku, H. Joshi, M. Ansari, S. K. Panda, S. Nayak, S. C. Dutta, A critical review and assessment for usage of recycled aggregate as sustainable construction material, Construction and Building Materials 131 (2017) pp 721-740.

doi: ttps ://doi .org/10.1016/j . conbuildmat . 2016.11.029

[17] K. Rahal, Mechanical properties of concrete with recycled coarse aggregate, Building and Environment 42 (1) (2007) pp. 407-415.

doi: https ://doi .org/10.1016/j . buildenv . 2005.07.033

[18] M. Rakshvir, S. V. Barai, Studies on recycled aggregates-based concrete, Waste Management and Research 24 (3) (2006) pp. 225-233. doi: $h t t p s$ ://doi .org/10.1177/0734242X06064820

[19] J. Sharma, S. Singla, Study of recycled concrete aggregates, International Journal of Engineering Trends and Technology 13 (3) (2014) pp. 1-5. doi: https://doi.org/10.14445/22315381/IJETT-V13P226

[20] C. S. Poon, Z. H. Shui, L. Lam, H. Fok, S. C. Kou, Influence of moisture states of natural and recycled aggregates on the slump and compressive strength of concrete, Cement and Concrete Research 34 (1) (2004) pp. 31-36. doi: https ://doi.org/10.1016/j . cemconres . 2003.12.019

[21] I. B. Topcu, S. Sengel, Properties of concretes produced with waste concrete aggregate, Cement and Concrete Research 34 (8) (2004) pp. 1307-1312. doi: https://doi.org/10.1016/j . cemconres . 2003.12.019 
[22] N. Fonseca, J. de Brito, L. Evangelista, The influence of curing conditions on the mechanical performance of concrete made with recycled concrete waste, Cement and Concrete Composites 33 (6) (2011) pp. 637-643.

doi: https://doi.org/10.1016/j . cemconcomp. 2011. 04.002

[23] M. Abed, R. Nemes, Long-term durability of self-compacting high-performance concrete produced with waste materials, Construction and Building Materials 212 (2019) pp. 350-361. doi: https ://doi .org/10.1016/j . conbuildmat . 2019. 04 . 004

[24] P. Chindaprasirt, T. Cao, Reuse of recycled aggregate in the production of alkali-activated concrete, in: Handbook of Alkali-Activated Cements, Mortars and Concretes, Woodhead Publishing, 2015, pp. 519-538. doi: https ://doi .org/10.1533/9781782422884.4.519

[25] J. P. B. Vieira, J.R. Correia, J. de Brito, Post-fire residual mechanical properties of concrete made with recycled concrete coarse aggregates, Cement and Concrete Research 41 (5) (2011) pp. 533-541. doi: $h t$ tps://doi.org/10.1016/j. cemconres.2011.02.002

[26] C. Laneyrie, A. Beaucour, M. F. Green, R. L. Hebert, B. Ledesert, A. Noumowe, Influence of recycled coarse aggregates on normal and highperformance concrete subjected to elevated temperatures, Construction and Building Materials 111 (2016) pp. 368-378. doi: ht tps ://doi .org/10.1016/j . conbuildmat . 2016. 02.056

[27] J. Z. Xiao, J. B. Li, C. Zhang, On relationships between the mechanical properties of recycled aggregate concrete: An overview, Materials and Structures 39 (2006) pp. 655-664.

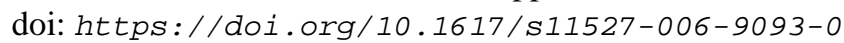

[28] J. Xiao, D. Lu, J. Ying, Durability of recycled aggregate concrete: An overview, Journal of Advanced Concrete Technology 11 (12) (2013) pp. 347-359. doi: https://doi.org/10.3151/jact.11.347 
[29] S. Pilehvar, A. M. Szczotok, J. F. Rodríguez, L. Valentini, M. Lanzón, R. Pamies, A. Kjøniksen, Effect of freeze-thaw cycles on the mechanical behaviour of geopolymer concrete and Portland cement concrete containing micro-encapsulated phase change materials, Construction and Building Materials 200 (2019) pp. 94-103. doi: https ://doi .org/10.1016/j . conbuildmat . 2018.12.057

[30] Ö. Çakır, Ö. Ö. Sofyanlı, Influence of silica fume on mechanical and physical properties of recycled aggregate concrete, HBRC Journal 11 (2) (2015) pp. 157-166.

doi: https ://doi .org/10.1016/j . hbrcj . 2014.06. $\odot \odot 2$

[31] I. H. Adebakin, T. O. Ipaye, Effect of elevated temperature on the compressive strength of recycled aggregate concrete, Research Journal of Engineering Sciences 5 (9) (2016) pp. 1-4. URL http://WWW. isca. in/IJES/Archive/v5/i9/1. ISCA-RJEngS2016-119.pdf

[32] D. Gao, L. Zhang, J. Zhao, P. You, Durability of steel fibre-reinforced recycled coarse aggregate concrete, Construction and Building Materials 232 (2020) Paper Nr. 117119

doi: https ://doi .org/10.1016/j . conbuildmat . 2019.117119

[33] M. Kunieda, N. Ueda, H. Nakamura, Ability of recycling on fibre reinforced concrete, Construction and Building Materials 67 (C) (2014) pp. 315-320. doi: $h t t p: / / d x$. doi.org/10.1016/j . conbuildmat . 2014.01.060

[34] W. M. Shaban, J. Yang, H. Su, K. H. Mo, L. Li, J. Xie, Quality improvement techniques for recycled concrete aggregate: A review, Journal of Advanced Concrete Technology 17 (2019) pp. 151-167. doi: https ://doi .org/10.3151/jact .17.4.151

[35] J. Xie, C. Fang, Z. Lu, Z. Li, L. Li, Effects of the addition of silica fume and rubber particles on the compressive behaviour of recycled aggregate concrete with steel fibres, Journal of Cleaner Production 197 (1) (2018) pp. 656-667. doi: https://doi.org/10.1016/j.jclepro.2018.06.237 
[36] C. Thomas, J. de Brito, A. Cimentada, J. A. Sainz-Aja, Macro- and micro- properties of multi-recycled aggregate concrete, Journal of Cleaner Production 245 (2020) Paper Nr. 118843. doi: https://doi.org/10.1016/j.jclepro.2019.118843

[37] Á. Salesa, J. A. Pérez-Benedicto, D. Colorado-Aranguren, P. L. López-Julián, L. M. Esteban, L. J. Sánz-Baldúz, J. L. Sáez-Hostaled, J. Ramis, D. Olivares, Physio - mechanical properties of multi - recycled concrete from precast concrete industry, Journal of Cleaner Production 141 (2017) pp. 248-255. doi: $h t t p: / / d x . d o i . o r g / 10.1016 / j$.jclepro.2016.09.058

[38] S. B. Huda, M. S. Aram, Mechanical behavior of three generations of $100 \%$ repeated recycled coarse aggregate concrete, Construction and Building Materials 65 (2014) pp. 574-582. doi: https : //doi .org/10.1016/j . conbuildmat . 2014. 05.010

[39] I. Marie, H. Quiasrawi, Closed-loop recycling of recycled concrete aggregates, Journal of Cleaner Production 37 (2012) pp. 243-248. doi: http://dx.doi.org/10.1016/j.jclepro.2012.07.020

[40] M. Abed, R. Nemes, B. A. Tayeh, Properties of self-compacting high-strength concrete containing multiple use of recycled aggregate, Journal of King Saud University - Engineering Sciences 32 (2) (2020) pp. 108-114. doi: https ://doi .org/10.1016/j . jksues . 2018 . 12 . 002 